\title{
INTEGRATED MOLTEN-SALT NUCLEAR REACTOR SYSTEMS FOR BASE-LOAD POWER PLANTS
}

\author{
R.G. BOOTHROYD \\ Chartered Engineer, Queensland, Australia.
}

\begin{abstract}
Molten-salt reactors (MSRs) can provide inexpensive industrial process heating in addition to generating electricity. In most cases, this can be best accomplished by design simplification, which results in improvements to MSR's already existing and inherently strong safety characteristics. This is just one of a number of possible future scenarios that will influence the way in which MSR technology can develop and become marketable. The emphasis in this paper is to develop a reactor with application to the widest possible range of industries. This paper concentrates on the need to develop the inherent safety characteristics of the single fluid thermal reactor with the expectation that sufficient reliability and safety will be achieved in design so that these power generators will eventually be accepted for close integration into the fabric of modern society. It seems inevitable that the required licensing procedures needed for MSRs will vary considerably depending on their type because different designs vary so much. Those used for low-temperature process heat in addition to power generation require much less demanding regulatory procedures than those operating at higher temperatures. This is largely because long-term corrosion is more problematic at higher temperatures and present-day construction materials limit the development of MSRs from reaching their full potential. With appropriate experience with operating early designs of MSRs it is reasonable to expect that lower temperature versions will become certifiable for use in close proximity to a large range of human activities. Ultimately these reactors will be controllable remotely without the local attendance of technical staff.

Keywords: molten-salt reactor, nuclear reactor control, nuclear technology, process heating.
\end{abstract}

\section{INTRODUCTION}

Although much has been written [1-8] about the technical advantages of MSRs using thorium and other fuels, little has been achieved with regard to commercial application to replace present-day outdated nuclear technology. The reasons are many. Prominent factors include: concerns with writing off expensive previous investment in LWR technology [2]; a competitive and strong fossil fuel industry under much pressure from global warming problems; unjustified public prejudice and mistrust of nuclear power [9] and a general lack of incentive except for addressing concerns about a changing climate.

As discussed in an earlier paper [10], the whole family of different MSRs provides a comprehensive and integrated system for providing our base-load energy needs in a fully closed cycle that also deals with the long-term problem of nuclear waste disposal. Thorium fuel reserves alone are sufficient for 1,000 years. Also the accumulated waste from earlier generation reactors, after treatment in fast MSRs, can become no more dangerous than uranium ore when it is first mined.

The earlier paper [10] suggested the need to develop a very simple reactor which could be mass-produced and used in a wide range of applications. The reasons given in this earlier paper were to overcome suspected looming emergency problems with climate change resulting from overuse of fossil fuels. This would require widespread increase in nuclear power to fill the gap. The present paper presents different, but supporting, arguments suggesting that this same type of reactor is seemingly the best way to 'kick start' the MSR industry. The reactor considered does not need much research/development and is seen as a highly profitable 
initial investment. In fact, it differs very little in concept from the original research at Oak Ridge $[11,12]$.

In 1976, a general purpose 'once through' reactor was designed at the Oak Ridge laboratories. It was called the denatured molten-salt reactor (DMSR) because its fuel was useless for nuclear weapons, consisting of a mixture mainly of low enriched natural Uranium and Thorium. There was no online fission product removal and reactivity was preserved at its minimum and safe level by the injection of additional fuel. The reactor was a converter making new ${ }^{233} \mathrm{U}$ fuel [12].

It was later argued [10] that widespread use of a version of this simplified modular reactor would provide the experience needed for the development of more sophisticated later designs of MSRs which we will need in the future.

\section{THE BROAD PICTURE IN DEVELOPING MSRS}

Figure 1 is a picture which is often used in documents related to MSRs. It demonstrates that MSRs are intrinsically and naturally high-temperature reactors operating at high thermal efficiency. Figure 1 shows this reactor powering a gas turbine, the hot exhaust of which may also be used to generate steam in an advanced co-generation unit. The theoretical (Carnot) efficiency of an MSR can be as high as $80 \%$, although in practice the maximum obtainable thermal efficiency achieved is more like $60 \%$ which is still commendably high. There are, however, strong arguments in favour of some MSR designs operating at much lower thermal efficiency.

As is the case in any engineering design, one can compromise between the good and not so good physical features of the system to obtain the optimum desired design so let us now address this point with regard to the reactor considered in this paper.

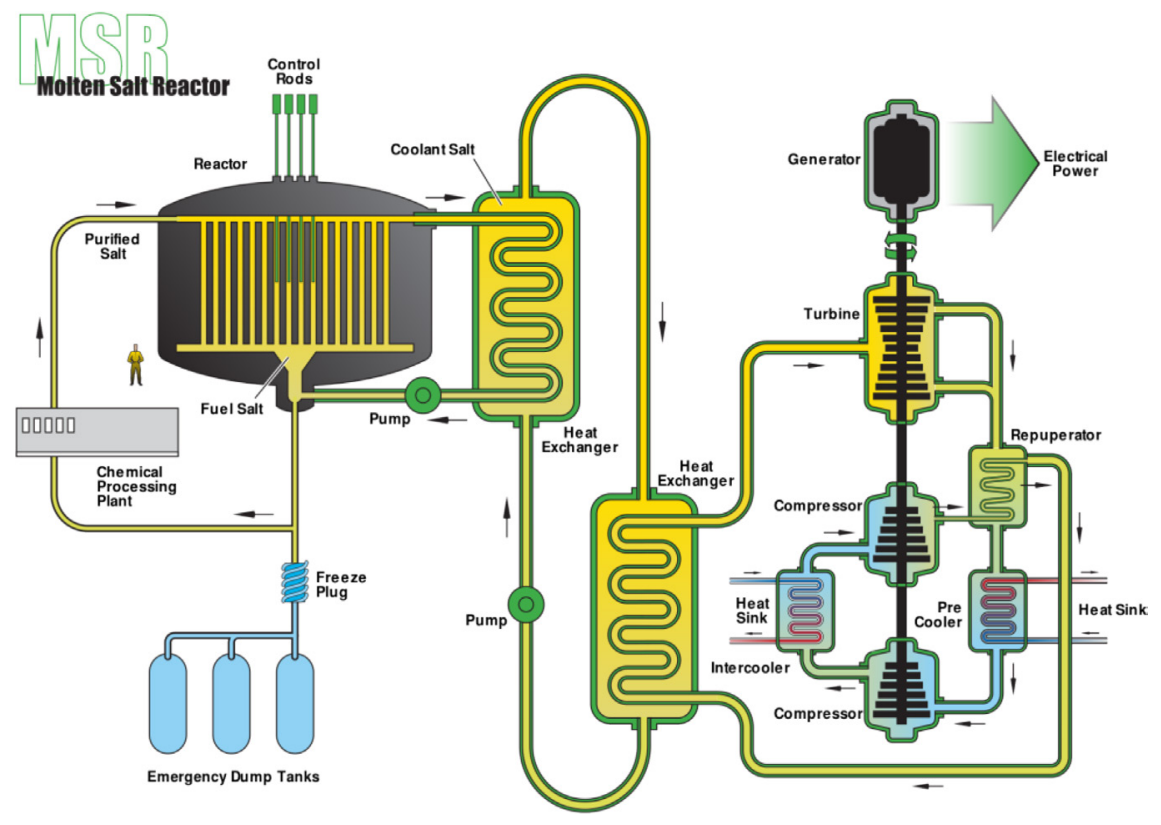

Figure 1: High-temperature MSR configured for use with Brayton gas turbine cycle (from Wikipedia Commons). 
The natural high thermal efficiency in MSRs is not so important because nuclear fuel costs are low and will remain low especially when most of the future fuel to be used will be thorium which is more abundant than uranium. Commercially a design should therefore orientate towards finding lower capital costs of construction while maintaining the excellent safety characteristics of the MSR. Both of these factors suggest adopting a policy of simplicity in design together with seeking a large market of application so that large numbers of mass-produced modular reactors can be sold at the least unit price. For all the above reasons, the single fluid thermal reactor has been selected as the most appropriate one for early commercialisation.

Experience gained with this simplified form of reactor would be beneficial in developing more advanced designs such as:

- The 2-fluid breeder thorium thermal reactor which is more complicated and is better suited to a large base-load generating facility. These reactors breed more fuel than they consume whereas the reactor considered in this paper is only a 'converter' producing less that one atom of fissile material for each fissile atom consumed.

- The fast MSR reactor, used to burn up accumulated actinide nuclear waste from using reactors of earlier design. This closes the nuclear cycle and renders final waste as disposable safely after about 300 years. Before ultimate disposal, this waste would be a valuable resource of rare and expensive elements generated by transmutation in the reactor [13].

- High-temperature reactors for the generation of hydrogen and the manufacture of synthetic fuels such as dimethyl ether for future road and rail transport.

- Thermal, epithermal (often this is the optimal neutron spectrum) and fast MSRs for unusual and specific purposes.

An example in this latter category is a reactor which may be needed quite often for low temperature process heat $\left(>100^{\circ} \mathrm{C}\right)$. We can examine a typical scenario where global warming and "warm-water" overfishing from overpopulation of our human species necessitates expanded large-scale fish-farming in places like Northern Canada, Russia, New Zealand's South Island, and perhaps even South Georgia. Large canneries may be needed in the summer fish-harvesting season, which close down in the winter, when the reactor would be used for domestic heating to sustain the resident human population. In this particular case, the basic universal reactor described in this paper can be configured easily for this application but it would use a different steam cycle rejecting heat in the condenser (item $\mathrm{C}$ in Fig. 2) to supply the process steam at the higher and variable temperature needed for the canning/domestic heating requirement. There is another necessary design feature in this application, namely that these remote places would limit reactor maintenance to an annual scheduled event and remote automatic control (see section 3.3) would be difficult, or even impossible, thus necessitating the attendance of qualified staff. Such a reactor would be a thorium-fuelled high performance converter using an automatic Protactinium $/{ }^{233}$ Uranium separator giving prolonged burn-up of the molten-salt fuel used (see section 5). Apart from this, 'add on' the reactor itself can be identical to those used in the rest of the world for a diversity of other purposes. This example also lends support to the concept of keeping the reactor design as small as is economically possible so that several small reactors can make up the facility needed. In this way, large-scale industrial activity can proceed at an acceptable level even if one unit has to be closed down due to a serious malfunction. 


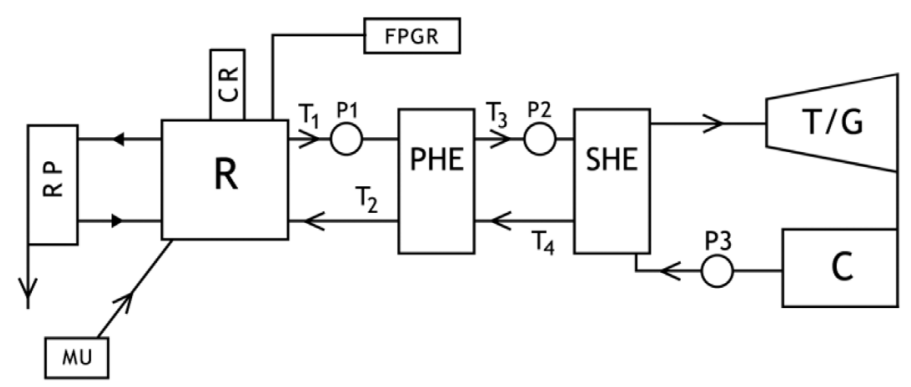

Figure 2: General schematic for all MSRs.

\section{MAIN DETAILS OF A SUGGESTED FIRST DESIGN}

Figure 2 illustrates comprehensively the features of all types of MSRs. In the single fluid outline design proposed, item RP is not used in the initial mark 1 version which would be supplied (MU in Fig. 2) with a recycled mix of 'make-up' plutonium and low enriched ${ }^{235} \mathrm{U}$ fuel. As there is no online fission product extraction, the two connections to the RP unit are therefore blanked off to allow conversion later to a reactor which mainly uses thorium. There is reasonable expectation of future improvements to the RP unit at a later date. This item would be heavily shielded and would be located in its own cavity in the reactor building (see section 3.3).

The control rods (CRs) of graphite are relatively small in this reactor where reactivity is maintained mainly by the continuous controlled injection of make-up fuel. In this type of reactor, CRs are moderators that are inserted to increase the reactivity. Reactivity is controlled mainly by the power which is drawn from the reactor. MSRs are natural good 'load followers' so that reactor control is mainly dependant on load demand (see section 3.2). Fission product gas removal [14] is for Krypton, Xenon and in this case Tritium (see the reasons for this in section (3.1.1)).

Reactivity control is also mainly by the steady continuous injection at MU of extra fuel. (see sections 3.2 and 4.1). The inlet and outlet temperatures for the reactor core are relatively low at $\mathrm{T}_{1}=700^{\circ} \mathrm{C}$ and $\mathrm{T}_{2}=565^{\circ} \mathrm{C}$. All the above features, including primary heat exchanger PHE in Fig. 2 are highly radioactive and are heavily shielded in an underground concrete structure which is not more than $10 \mathrm{~m}$ deep. The hot-molten salt from PHE is used to generate steam in the secondary heat exchanger SHE, and this salt is different from that used in the primary circuit PHE (see section 4).

\subsection{Gaseous fission product collection}

${ }^{135} \mathrm{Xenon}$ is a gaseous fission product which is a strong poison (absorbs thermal neutrons). Gaseous fission products are 'outgassed' automatically in all MSRs which is far superior to retaining these fission products in encapsulated fuel rods. ${ }^{135} \mathrm{Xe}$, Krypton and Tritium are outgassed and collected for decay/disposal [14].

\subsubsection{Tritium control}

All nuclear reactors, even including fusion reactors, emit Tritium and its release is strictly controlled. Tritium is radioactive with a half-life of 12 years, emitting a beta particle which is so lacking in energy that it cannot penetrate our outer skin. Nevertheless Tritium is injurious 
to health because it oxidises to Tritiated water $\left({ }_{1} \mathrm{H}_{2}^{3} \mathrm{O}\right)$ which, when it has mixed with ordinary water, will be ingested to damage our delicate internal tissues. Ingested water has a biological half life of about 10 days, roughly-speaking, depending on the individual and the seasonal climate. This is enough to be a health hazard. When this proposed reactor is intended for use in close proximity to people, Tritium collection is incorporated and it is not released to the environment. Apart from military uses, Tritium is of some industrial value such as for painting luminous dials. A scintillation-counter would monitor malfunction of the Tritium control unit. Tritium occurs naturally from cosmic radiation and is a small component of natural background radioactivity.

\subsection{Reactivity control}

One of the most important reasons for the superiority of the MSR concept over traditional reactor designs lies in the very different mechanism of power control. Control systems can be 'passive' i.e. they are automatic, or they are 'active' which means that the control is by a humanly-engineered system.

Encapsulated fuel reactors are largely in the active control category. Poisons build up in the fuel elements so that extra reactivity must be designed into the reactor. This is reduced by the insertion of neutron-absorbing control rod. Consequently great care is needed in moving control rod. Withdrawing them too fast caused the Chernobyl accident. This built-in extra reactivity is a danger in all traditional nuclear plant. All MSRs avoid this feature as reactivity in the molten salt is increased slowly and continuously as burn up proceeds and is never present in excess to give a power surge from prompt neutrons alone. Exploiting the high generation speed of prompt neutrons is only of interest in the design of nuclear weapons.

Traditional reactors rely on an unusual class of fission products in the reactor called delayed neutron emitters [15]. About 6 of these are relevant. They suffer radioactive decay and emit a neutron which adds to the chain reaction when the reactor is close to critical. Normally when the reactor is changing its delivered power, these neutrons from radioactive decay delay the control response according to the half-lives of these delayed neutron emitters. In fact, without this effect from delayed neutrons, it would be near impossible to design a safe nuclear reactor. If control rod are pulled out too fast by accident, the chain reaction can proceed by the production of prompt neutrons and this is where it is possible for a sudden runaway power surge to cause melt-down. In traditional reactor design these delayed neutrons enable reactors to be controlled safely.

MSRs are completely different [16]. The main control mechanism is from thermal expansion from the near-incompressible molten fuel. When less power is drawn from the reactor, the molten salt heats up and expands ejecting part of the reacting fuel/coolant from the core to reduce the nuclear reaction. Voids produced by gaseous fission products also decrease reactivity and also act beneficially in control. Delayed neutron emitters spend less time in the MSR core and are about half as effective as in traditional reactors. On the opposite side, giving adverse positive feedback, graphite deteriorates in a high neutron flux to give an opposite effect to the natural automatic shutdown from an expanding coolant/fuel. However, the effect is small and can be kept so with good design. Nevertheless, graphite is a useful and relatively cheap moderator and reduces the fuel inventory needed. Fast MSRs, which use no moderator at all, need about 10 times the amount of molten salt for the same power rating and this affects their economics.

To summarise, the power control of a traditional encapsulated fuel reactor is dependent on many factors, many of which are 'active'. Thus, great care is needed in designing a control 
system where both passive (inbuilt negative feedback characteristics) operate together with other both positive and negative active feedback which involves the movement of control rod. MSRs have a much more simple 'passive' control. Also some of the worst reactor poisons such as ${ }^{135} \mathrm{Xe}$ are continuously 'outgassed' in MSRs and do not build up in the fuel elements, which are absent in MSRs. Criticality in an MSR is maintained at almost the exact level by a small and very slow continuous injection of extra fissile material as it operates. In more advanced designs it is also possible to extract the more important fission fragments continuously, reducing the need for extra fuel.

The net result is that the MSR is effectively controlled by its core temperature only because the active control is very small in comparison. If extra power is drawn from an MSR, its reactivity increases automatically as the molten salt in the core cools. When less power is drawn from the reactor, the slight increase in core temperature shuts the reactor down automatically. We call this effect "having a good load-following characteristic".

In short, the MSR reactor family has a very simple and automatic control system. Early designs also incorporated a fan-cooled fusible plug in the reactor base which would melt and discharge the molten salt into a subcritical set of containers if power to the reactor plant failed as happened at Fukushima. This simple safety system, shown in Fig. 1 is still used in many designs but the need for it is questionable.

\subsection{Maintenance}

It is considered that this very basic and safe form of nuclear reactor makes it ideal for automatic control, even without the need for skilled operatives in attendance, except for security guards at ground level. The reactor's performance data can be transmitted continuously in real time to a certified regulatory authority so that remote control is feasible. Any unusual/ emergency action can be under the control of the authority's computer system. It is suggested that this same authority would also be the organisation providing the make-up fuel, and all maintenance and disposal using its own recycling/repair facilities. The reactor owner merely draws off power as required and is not involved with technical matters.

Maintenance often bears a strong resemblance to that required in aWR when it is depressurised. On-site maintenance is easier in a reactor such as an MSR which operates at atmospheric pressure. Maintenance tasks vary in size. It would be a relatively small task to replace a defective MSR pump. Replacing the core assembly, although a much larger task, would still be a routine job. The latter task can also be simplified in most cases. It is easy to pump old MSR fuel remotely (after poisoning it) from the core to a cooling chamber. Changing the whole reactor vessel and making a remote inspection of the inside of a very old reactor chamber by remote methods would be similar to the routine used with today's LWRs.

It also seems reasonable that these tasks can be carried out using road transport for access. This on-site maintenance is only an extension of the present-day carriage of highly-radioactive materials which has a good record of safety. British Nuclear fuels (Springfield Division) makes about 50 articulated vehicle trips each week [17] all over Europe and has been doing this safely for 40 years. Depending on the size of the maintenance job, more than one of these trucks could also carry remote-handling equipment and trained staff in addition to transporting radioactive materials back to base. On-site maintenance using road transport is a factor in choosing a small standard design of reactor. Small multiple and identical reactor units would also be preferred by large energy users who cannot accept expensive down-time problems for maintenance of a large reactor. 
There would be similarities with present technology using LWRs. For example when changing the coolant/fuel or replacing the reactor core, the first task would be to remove the contents of the cooling cavity (which is similar in function to the cooling pond in a typical LWR but is close to the reactor in an open-topped cavity). Normally, this cavity would already hold a container of solidified salt-fuel removed about 3 years ago in a previous standard maintenance. Alternatively, the cooling cavity may contain a 3-year-old defective core by which time fission product radioactive decay also would make for safer handling problems. When any existing item in the 'cooling' cavity has been removed and 'casked' for transfer back to base, maintenance can be started. Old fuel/coolant would be poisoned and pumped into a container in the cooling cavity. In the case of core replacement, the whole core is placed in the cavity for radioactivity to decay, and the new core is then installed. All these tasks are carried out by remote-handling which is a well-established technology in today's nuclear industry.

The choice of the single fluid reactor in preference to a 2-fluid design is dictated by the necessary simplicity of the plumbing connections where handling is remotely controlled. A 2-fluid design, having more plumbing connections would make remote handling too difficult.

\subsubsection{Security against terrorist activity}

Terrorism seems likely to be a permanent feature of modern society. It is also a feature for which remedies are limited. The reasons are many and varied and outside the scope of this paper. As just one illustrative example, increasing unemployment arises from increased automation in manufacturing which is advantageous for society in general [18]. Some well-educated young people may have minor personality problems in adapting to today's very competitive corporate-style world. Their reasonable feelings of frustration may take many, and occasionally undesirable, forms. The nett result is that the burden of reducing vulnerability to terrorism will become much more of an engineering design responsibility.

Fortunately, the MSR is well equipped to become a very 'hard' target for terrorists. Japan's Fuji reactor which is similar in design to the example examined here will be built underground, an approach favoured by many MSR experts. Secondly, the MSR control system is easily made tamper-proof. Even if computer hacking interfered with remote control data transmission, it is easy to incorporate automatic over-riding control within the sealed reactor building. This might follow the following procedure.

Stage 1: An inconsistent transient is experienced causing the reactor to overheat. It reduces its reactivity automatically. No other action is taken.

Stage 2: If the fault repeats itself, fuel to the MU (make up) line is cut off and power off-loading starts. There is no alternative to the reactor closing down.

Stage 3: The incident is investigated from online data received, and the owner is contacted. A human executive decision is made at headquarters (section 7) if criminal activity is suspected.

There is no need to use drastic shutdown methods such a reactor poisoning or melting a drainplug in the reactor base.

\subsection{Optimising design}

Decisions related to the optimum size of this standardised basic reactor are a very complicated task. Apart from customer requirements, the effect of plant size on capital costs needs 
detailed study. MSRs can be built easily in a variety of sizes, and although size reduction would tend to increase installed cost per kilowatt, size reduction can also result in simplification and reduced costs. For example, as is the case in all power stations, expensive gantry cranes are a necessary installation because of the heavy lifting required. In an MSR, all maintenance needs remote-handling techniques with which the nuclear industry has high skills. It may be possible to design a remotely self-installing lifting system which can be brought by road to use on a standardised reactor. This approach places limits on the size of the reactor.

The design of an optimum system is a very lengthy and demanding task and is outside the scope of this paper.

\section{MOLTEN SALTS USED}

A variety of molten-salt eutectics are suitable for use in MSRs. Lithium and Beryllium fluorides (called FliBe) melt at $459^{\circ} \mathrm{C}$ and constituents $\mathrm{F},{ }^{7} \mathrm{Li}$ and $\mathrm{Be}$ all have low thermal neutron absorption cross sections. Their small atomic weight also enhances their neutron moderating effect and they are completely stable in the high neutron flux of a reactor due to their molten ionic state. ${ }^{7} \mathrm{Li}$ is moderately expensive and has to be separated from its other isotope ${ }^{6} \mathrm{Li}$ which breaks down to Tritium in a high neutron flux. Also the neutron absorption cross section of ${ }^{6} \mathrm{Li}$ is a hefty 940 barns compared with ${ }^{7} \mathrm{Li}$ at 0.045 barns. Fortunately ${ }_{3}^{7} \mathrm{Li}$ is easily separated from its lighter isotope in a column exchange method as the lighter isotope has a stronger affinity with mercury. An alternative laser separation method can be used. This separation is of major industrial interest as the lighter isotope is preferred in Li-ion batteries and for military purposes.

In the secondary molten-salt circuit (SHE in Fig. 2) an alternative molten-salt eutectic (sodium, potassium fluorides) has a melting point of $454^{\circ} \mathrm{C}$ and avoids the toxicity of Be in this very low radioactive part of the circuit which is outside the main reactor shielding. Fast MSRs can use lead fluorides because of the very small neutron moderating effect of lead.

Some successful work has been carried out using molten chloride salts instead of fluorides. To the best of the Author's knowledge, no significant work has been carried out using bromine-based salts.

${ }^{7} \mathrm{LiF}$ is an expensive salt and LeBlanc says that $\mathrm{NaF}_{-} \mathrm{BeF}_{2}$ or NaF-RbF work well enough and are much cheaper. Normally, the SHE circuit in Fig. 2 never uses ${ }^{7} \mathrm{LiF}$. Other suitable eutectics are $\mathrm{ZrF}_{4}-\mathrm{NaF}-\mathrm{KF}, \mathrm{ZrF}_{4}-\mathrm{KF}$ or $\mathrm{NaF}-\mathrm{BeF}_{2}$ although the latter is toxic.

\subsection{Fuels used}

As illustrated in Fig. 2 at MU, one of the advantages of MSRs is that fuel is injected continuously to keep the reactivity at the desired level. This injection equipment would be outside the main reactor shielding in a secure compartment but the injection conduit leads to the security valve described in section 3.3.1. The certified support authority described in section 7 is responsible for this fuel injection equipment and the supply of the 'make-up' fuel mix itself. This make- up fuel may contain ${ }^{233} \mathrm{U},{ }^{235} \mathrm{U}$ and various mixed isotopes of plutonium together with fertile material such as natural uranium, depleted uranium and thorium. MSRs work with any of these composite fuels injected in fluoride form. However, the fuel injection must be designed correctly by a qualified nuclear specialist.

The support authority would usually make these fuels from spent fuel elements from today's LWRs. These earlier reactors can only use up to $5 \%$ of the available fuel before the fuel elements have to be chopped up and the remaining fuel is reprocessed for further use. 
MSRs use a higher proportion of the fuel and this can exceed $50 \%$ in advanced versions of the reactor described here which incorporate online fission product extraction in addition to new ${ }^{233} \mathrm{U}$ injection as described in section 5. The spent fuel from this class of thermal reactor type MSR would then be subjected to the final reprocessing stage for use in fast MSRs which burn up the remainder of all fissile material leaving only short half-life fission products which must be stored for 300 years before safe disposal. In this system, all the fuel would be used up eventually to produce useable energy.

\section{CONVERTING THE REACTOR TO THORIUM FUEL}

Breeding ${ }^{233} \mathrm{U}$ from Thorium has a nuisance factor which cannot be avoided easily. This is the generation of the intermediate product ${ }^{233}$ Protactinium. The formation is given by:

$$
{ }_{90}^{232} \mathrm{Th}+{ }_{0}^{1} \mathrm{n} \rightarrow{ }_{90}^{233} \mathrm{Th} \rightarrow{ }_{91}^{233} \mathrm{~Pa} \rightarrow{ }_{92}^{233} \mathrm{U} .
$$

Here, the ${ }^{233}{ }_{90}$ Th decays by beta particle- emission to ${ }_{91}^{233} \mathrm{~Pa}$ with a short half-life of 22 mins. This does not cause a serious problem because significant amounts of unwanted reactions cannot take place when the half-life is so short. However, the subsequent beta- emission $\left({ }_{91}^{233} \mathrm{~Pa} \rightarrow{ }^{233}{ }_{92} \mathrm{U}\right)$ has an inconveniently long half-life of 27 days. As ${ }^{233}{ }_{91} \mathrm{~Pa}$ has a large thermal neutron absorption cross section, it is desirable to separate $\mathrm{Pa}$ from the Uranium it breeds. This is easy enough by bubbling fluorine through the molten salt to remove the ${ }^{233} \mathrm{U}$ which is in salt form as $\mathrm{UF}_{4}$ and then fluorinates readily to $\mathrm{UF}_{6}$ which is gaseous. Subsequent reduction of the hexafluoride to $\mathrm{UF}_{4}$ allows the newly bred fuel to be reinjected back into the reactor. The problem is that the 27 day beta particle decay half-life increases the residence time needed for the Protactinium to decay to the new fuel and this increases costs.

This consideration justifies the suggestion that the reactor should be designed for use initially with uranium/plutonium mix fuels with the option to convert to thorium fuel later with an add-on facility which is also quite large and requires heavy shielding. Uranium/plutonium fuels work well in MSRs but eventually supply problems may require using the $\mathrm{Th} /{ }^{233} \mathrm{U}$ fuel cycle.

It is possible to avoid the expense of Protactinium/Uranium separation but at a cost of reduced performance of the thorium-fuelled reactor. Table 1 shows data supplied by Dr David LeBlanc in a blogspot thread. Blogspots can provide useful information as MSR experts often communicate this way. As mentioned earlier [10, p. 81), experts in MSR technology also often communicate using some well-organised audio visual presentations.

Table 1: Converter/breeder characteristics of 4 different reactor designs.

\begin{tabular}{llccc}
\hline Reactor type & $\begin{array}{l}\text { Protactinium } \\
\text { treatment }\end{array}$ & $\begin{array}{c}\text { Neutrons } \\
\text { per fission }\end{array}$ & $\begin{array}{c}\text { Lost neutrons } \\
\text { per fission to Pa }\end{array}$ & $\begin{array}{c}\text { Lost neutrons per fission } \\
\text { to } \mathrm{Pa}+{ }^{233} \text { U but not fission } \\
\text { products }\end{array}$ \\
\hline $\begin{array}{l}\text { A single fluid } \\
\text { B single fluid }\end{array}$ & $\begin{array}{l}\text { No removal } \\
\text { 3dayresidence } \\
\text { time removal }\end{array}$ & 2.23 & 0.05 & 0.1 \\
C 2 fluid & $\begin{array}{l}\text { Large breeder } \\
\text { blanket no Pa } \\
\text { (ORNL1467) }\end{array}$ & 2.22 & $7.9 \times 10^{-3}$ & $3 \times 10^{-3}$ \\
$\begin{array}{l}\text { removal } \\
\text { D 2 fluid }\end{array}$ & $\begin{array}{l}\text { Smaller breeder } \\
\text { (ORNL4528) }\end{array}$ & 2.22 & $2 \times 10^{-4}$ & $1.6 \times 10^{-2}$ \\
& removal + Pa & & & $4 \times 10^{-4}$ \\
\hline
\end{tabular}


Reactor A is the type considered in the present paper. Initially, the reactor acts as a breeder producing about 1.08 new atoms of fuel for each atom burnt. However this figure falls as the fission products increase. This is when the nett value in column 3 falls below 2. Eventually the thorium conversion to uranium falls to the level when it is no longer economical and the fuel is changed. Reactor B is essentially the same as reactor A except that the Pa is kept for 3 days with fluorination removing the new uranium fuel. This prolongs the life of the fuel and may be useful in the reactor for the fish cannery described in section 2 .

It is worth reminding ourselves that the reactor described in this paper is a versatile design and can be used in several ways. Desalination, both reverse-osmosis and evaporative; domestic heating; integrated industrial complexes; multiple unit base-load systems and isolated plant in less-developed nations are obvious examples.

Reactors C and D in Table 1 are too complicated for general use but would eventually be used as efficient uranium breeders producing more fuel than they would consume. They would comprise part of a base-load power station and are also likely to use some form of online fission product removal as this improves fuel breeding. Typically, these reactors would be found in the central reprocessing facility mentioned in section (7) so that the right fuel make-up mix can be formulated and distributed to clients using the type A reactor.

\section{INVESTMENT PROBLEMS WITH MSRS}

So much of the success in developing modern technology is owed to earlier military interests. This is especially true of the development of nuclear fission power. In UK, for example, manufacture of weapons-grade ${ }^{239} \mathrm{Pu}$ at Windscale lead to the higher temperature gas-cooled reactors, which, for a time, held out promise for development worldwide. In USA, a proportionately larger enterprise gave us the Nautilus, the world's first operational nuclear submarine. It was logical that the experience gained should be commercialised to give us the PWR and its close relative, the BWR. Understandably, it was the direct military experience which led to the dominance of the PWR as the world's leading commercial system. There are many other similar examples of the value of military research in present-day commercial technology. For example, perhaps today's deadly drone aircraft may eventually lead to inexpensive pilotless cargo-carrying aircraft [19] where, once again, the military technology is easy to adapt.

However, the fact remains that there is no such military stimulus today for developing MSRs. A similar stimulus however exists in the concern of over-using fossil fuels which cause climate degradation where electricity generation is a prime contributor. Nevertheless maintenance of grid power in our cities is now an essential component in preserving our human civilisation and widespread use of MSRs with their outstanding safety features seems to be the solution we are seeking.

The emphasis in this paper is on the high level of MSR safety and the potential for low capital cost through modular construction and basic simplicity. Our superannuation industry is always looking for good forms of long-term investment and this form of MSR seems to be one of them. Ideally, the US is the place to start and there is a good argument for public taxpayer support for these skilled nuclear industries to overcome the problems of outdated technology. It would be a tragedy if the nation which invented the MSR was to get left behind. There is a warning from history. The UK was once a leader in developing nuclear power but its research effort has almost dwindled into non-existence [3, dgm on page 8] and the consequences are very apparent [20].

Most high tech industries result from amalgamation into big global corporations and three is a very common number. Aviation gas turbines, for example, offer us a choice of 3 such corporations. The big future nuclear power conglomerates also seem likely to become 3 in 
number. Bearing in mind the need for substantial home markets, the first of these is likely to be in Asia [10], the second in Europe which should include Russia as an equal partner with France needing the technology most and advantaged by the industrial strength of Germany and several smaller nations on its doorstep. The third such global corporation is seen as serving the North and South American continents.

\section{TOWARDS AN MSR FUTURE}

The simplified design outlined above stresses the need for a reactor which is supported by a certificated and accredited maintenance service which is also responsible for the supply of the top-up fuel mix to be used. These organisations could also be the responsible nuclear authority.

It seems reasonable that basic thermal MSR reactors would eventually become fully automated and the only on-site human staff needed would be security personnel. Operating data from such unsupervised plant would be transmitted continuously in real time to the appropriate nuclear authority which can exercise primary safety and deploy support services when needed. This raises the question of the design of this necessary 'headquarters' part of the MSR infrastructure. At this stage, it is difficult to be specific with regard to this vitally important component in the design.

Ideally, a small number of such support units would be responsible for the refabrication of exchanged equipment from the basic reactors. These support units would also be spent fuel repositories where containerised reactor salts, now solidified at room temperature, are stored non-critically below ground in vaults awaiting reprocessing. These could be accessible from an automated rail network using standard remote-handling equipment. All reprocessing and the manufacture of MSR top-up mixes would need to be fully automated using remote handling.

These reprocessing plants would have their own fleet of maintenance vehicles as mentioned above. Because of their large size, siting MSR support organisations would be a sensitive issue because this is a large complicated high tech industry to support many very simple reactors.

These reprocessing facilities would also use fast actinide-burning reactors acting as baseload electricity generators which reduce the waste to a form where valuable transmuted elements can be extracted before the waste is removed to storage for 300 years when the remaining fission products will have decayed to an acceptable level.

Reprocessing involves complicated chemistry and many technical alternatives present themselves for comparative appraisal in designing reprocessing plant. Even re-melting the used salt fuel for processing raises the question of the best method. Would this be carried out using a linear proton accelerator to melt a solidified subcritical assembly of used fuel? However these powerful accelerators are large, expensive and their reliability is questionable. Would the alternatives of inductive heating be used or would resistive heating be used? Such questions are outside the scope of this paper but we are already starting to acquire some experience in these matters.

\section{DISCUSSION}

Important advances in science and technology can sometimes be described as 'serendipitous' or 'unexpected, beneficial and found by chance'. Nuclear technology is no exception.

It was the strange nature of delayed neutron emitters [15] which enabled the atomic bomb to be controlled to release its energy slowly for peaceful use. Our earlier nuclear industry deserves much respect and credit for its good engineering which allowed us to exploit an inherently dangerous form of energy for so many years with so few accidents. 
Serendipity has come to help us once again. The molten-salt reactor, inherently a high-temperature device, offers us the prospect of even safer nuclear power, if we use it in its less natural form as a low-temperature device. MSRs embody a new and far better control system which we can use to our advantage.

\section{CONCLUSIONS}

When designed for moderate temperature use, a basic single fluid molten-salt nuclear reactor has the potential to become the safest of all nuclear reactors. It would also be marketable for a wide variety of industries. The list of industrial applications seems almost endless. In due course, it is expected that appropriate regulation will allow many such designs to be used in close proximity to other amenities of human society. Although the concept of a remotely-controlled basic thermal nuclear reactor without technical staff in attendance may seem revolutionary, it seems to be a logical development on technical grounds.

The further development and adoption of MSR technology is hampered by the huge earlier investment in reactor concepts which are now outdated in the light of the MSR system. Because we are faced with coping with the present oversized world population, a huge expansion in nuclear fission power seems to be the only realistic way to satisfy our future energy needs, MSRs present a huge, yet very attractive, investment opportunity which fortunately coincides with the worldwide increase in private employee superannuation schemes.

There are concerns that the United States, where the MSR was invented, is falling behind in MSR technology. It is concluded that public tax-payer funding is desirable to remedy this problem.

MSR technology is undergoing faster development in Asian nations than in Europe and America. Whereas this may suit those of us living in the Far East, this is not in the best interest of the world at large which needs at least 3 global corporations to sustain the vitality of the future MSR industry.

It is also concluded that existing nuclear regulation authorities are unsuitable for licensing MSR systems. This is because the new technology is so radically different. It is suggested that the combined regulating and servicing form of authority, outlined in this paper is a more appropriate method of ensuring public safety.

\section{ACRONYMS}

BWR boiling water reactor (similar in many ways to a PWR)

LWR liquid water reactor (this includes PWRs and BWRs)

MSR molten-salt reactor

ORNL Oak Ridge National Laboratory, Tennessee, USA

PWR pressurised water reactor. Uses ordinary light water as coolant and moderator

\section{REFERENCES}

[1] Kamei, T., Recent research of thorium molten-salt reactor from a sutainability viewpoint. Sustainability, 4(10), pp. 2399-2418, 2012. http://dx.doi.org/10.3390/su4102399

[2] Hargraves, R. \& Moir, M., Liquid fluoride thorium reactors. American Scientist, 98, pp. 304-313, 2010. http://dx.doi.org/10.1511/2010.85.304

[3] Energy Process Developments, MRS review:feasibility of developing a pilot scale molten salt reactor in the U.K, available at www.EnergyProcessDevelopment.com pp. $1-74,2015$. 
[4] Ho, M.K.M., Yeoh, G.H. \& Bracudakis, G., Molten salt reactors. Materials and Processes for Energy, Formatex, ed. A. Mendes-Vilas, pp. 761-768, 2013.

[5] Touran, N., Molten salt reactors, available at http://whatisnuclear.com $/ \mathrm{msr} . h t m l$

[6] Lerner, G., available at http://liquidfluoridethoriumreactor.glerner.com/2012-downsides-of-lftrs/

[7] Anon, Thorium MSR: Pros and Cons, Nucleargreen blogspot, available at http:// thoriummsr.com/intro/pros-and-cons-list/

[8] World Nuclear Association, available at http://www.world-nuclear.org/InformationLibrary

[9] Herbst, A.M. \& Hopley, G.W., Nuclear Energy Now: Why the Time has Come for the World's Most Misunderstood Energy Resource, John Wiley: Hoboken, NJ, pp. 1-230, 2007.

[10] Boothroyd, R.G., A suggested roadmap for world-wide energy resource planning and management. International Journal of Energy Production \& Management, 1(1), pp. 72-86, 2016. http://dx.doi.org/10.2495/EQ-V1-N1-72-86

[11] Forsberg, C.W., Thermal- and fast-Spectrum Molten Salt reactors for Actinide Burning and Fuel Production, Global 07: Advanced Nuclear Fuel Cycles and Systems, American Nuclear Society, manuscript number 175768, Boise, Idaho, September 9-13, 2007.

[12] LeBlanc, D., Too good to leave on the shelf. Mechanical Engineering, 132(5), pp. 28-33, 2010.

[13] Ignatiev, V.V., Feynberg, O.S., Zagnitko, A.V., Merzlyakov, A.V., Surenkov, A.L., Panov, A.V., Subbotin, V.G., Afonichkin, V.K., Khokhlov, V.A. \& Kormilitsyn, M.V., Molten salt reactors:new possibilities,problems and solutions. Atomic Energy, 112(3), pp, 157-165, 2012.

[14] Soelberg, N.R., Garn, T.G., Greenhalgh, M.R., Law, J.D., Jubin, R., Strachan, D.M. \& Thallapally, P.K., Radioactive iodine and krypton control for nuclear fuel reprocessing facilities. Science and Technology of Nuclear Installations, Article ID 702496, p. 12, available at http://dx.doi.org/1155/2013/702496, 2013.

[15] Keepin, G.R., Wimett, T.F. \& Zeigler, R.K., Delayed neutrons from fissionable isotopes of uranium, plutonium and thorium. Physical Review, 107, p. 1044, 1957.

http://dx.doi.org/10.1103/PhysRev.107.1044

[16] Elshiekh, B.M., Safety assessment of molten salt reactors in comparison with light water reactors. Journal of Radiation Research and Applied Sciences, 6, pp. 63-70, 2013. http://dx.doi.org/10.1016/j.jrras.2013.10.008

[17] Anon., No glow-just wash and dry: a white paper (free subscription required for access), available at powertechnology.com 15 November 2015.

[18] Boothroyd, R.G., Urban planning for emergent technologies, new life-styles and a changing environment. WIT Transactions on Ecology and the Environment, 179, pp. 93-107, 2013.

http://dx.doi.org/10.2495/SC130081

[19] Boothroyd, R.G., A proposed extra international air corridor along the world's equatorial belt, paper 1067. General Proceedings, 12th World Conference on Transport Research, Lisbon, 2010.

[20] Pearce, F., New delays hit Sellafield clean up. NewScientist, 225(3005), pp. 8-9, 2015. http://dx.doi.org/10.1016/S0262-4079(15)60145-2 